Case Report

\title{
Resurgence of Diphtheria - A case report
}

\author{
Wadekar M.D. ${ }^{1}$, Sathish J.V. ${ }^{2}$ \\ ${ }^{1}$ Dr. Mita D. Wadekar, Assistant Professor, ${ }^{2}$ Dr. Sathish J.V, Associate Professor, Department of Microbiology, \\ Chamarajanagar Institute of Medical Sciences, Chamarajanagar, Karnataka, India.
}

Corresponding Author: Dr. Sathish J.V, Associate Professor, Department of Microbiology, Chamarajanagar Institute of Medical Sciences, Chamarajanagar, Karnataka, India. Email: javagalsathish37@gmail.com,drmdw20@gmail.com

\begin{abstract}
Diphtheria is a highly infectious and one of the most common causes for childhood mortality. In developed countries, diphtheria has been completely eradicated with the introduction of effective immunization program. In developing countries like India, the incidence of this disease has declined with immunization. But resurgence has been reported from many parts of India. Poor immunization coverage and failure to take booster doses is responsible for persistence of diphtheria. Here we report a case of diphtheria in a 6 year old boy from Chamarajanagar district.
\end{abstract}

Key words: Diphtheria, Resurgence, Immunization

\section{Introduction}

Diphtheria is an infectious and notifiable disease caused by Corynebacterium diphtheriae. It continues to be endemic in India and is the leading cause of morbidity and mortality [1]. The symptoms include sore throat, malaise and low grade fever. The characteristic feature of diphtheria is a grayish-white pseudo membrane which bleeds on removal on the pharynx, larynx and the tonsils which can extend into the larynx causing airway obstruction and death [2]. The regional lymph nodes in the neck enlarge, and there may be marked edema of the entire neck. Pathogenesis of diphtheria is toxin mediated. Diphtheria is toxemia but never a bacteremia [3]. Toxin, which is produced by $C$. diphtheriae, spread by blood stream to various organs. Polyneuropathy and myocarditis are the rare manifestations, occurring after weeks ofinfection. Neurologic manifestations are no inflammatory demyelinaling disorder [4]. Age incidence of this disease is being shifted from below 5 years to above years. The reasons for high mortality are poor immunization coverage, failure to take booster doses, poor socio-economic standards, delayed reporting to hospital, non-availability and delay in administration [5,6]. Microbiological diagnosis plays an important role in early detection of infection and early institution of diphtheria antitoxin may save lives. Delay in diagnosis may increase mortality and the risk of transmission [7]. Here we report a case of diphtheria in a 6 year old boy from Chamarajanagar district.

\section{Case Report}

6 year old boy was brought to paediatric OPD with chief complaints of fever and throat pain since 5 days. On examination, patient was conscious with pulse rate and temperature of $110 / \mathrm{min}$ and $39.4^{\circ} \mathrm{C}$ respectively. As the patient also had swelling in anterior part of neck and difficulty in breathing, he was referred to ENT department for evaluation. On oral examination, pharynx was congested and both tonsils were enlarged with small greyish white membrane present on the surface. There was bleeding when an attempt was made to remove the patch. A provisional diagnosis of diphtheria was made. Two throat swabs from tonsillar area were sent for microbiological investigation which included direct examination by Gram stain and Albert stain and for culture and sensitivity.

Gram stain (Figure 1) showed Gram positive bacilli with swollen ends arranged in parallel and angular fashion. Albert stain (Figure 2) showed green coloured bacilli with black granules at their ends. Sample was inoculated onblood agar, potassium tellurite agar and Loefflers serum slope. Colonies on blood agar were white, small, circular, and hemolytic. Potassium tellurite agar showed black colonies and on Loefflers serum slope the colonies were small, circular

Manuscript received: $18^{\text {th }}$ October 2018

Reviewed: $28^{\text {th }}$ October 2018

Author Corrected: $4^{\text {th }}$ November 2018

Accepted for Publication: $7^{\text {th }}$ November 2018 


\section{Case Report}

white opaque, enlarged with a distinct yellow tint on continued incubation. It was sensitive to Penicillin, Erythromycin, Ciprofloxacin, Ceftriaxone and Cefotaxime. Treatment started with erythromycin in isolation ward, diphtheria antitoxin was not administered due to unavailability. Patient was immediately referred to higher centre for antidiphtheric serum (ADS).

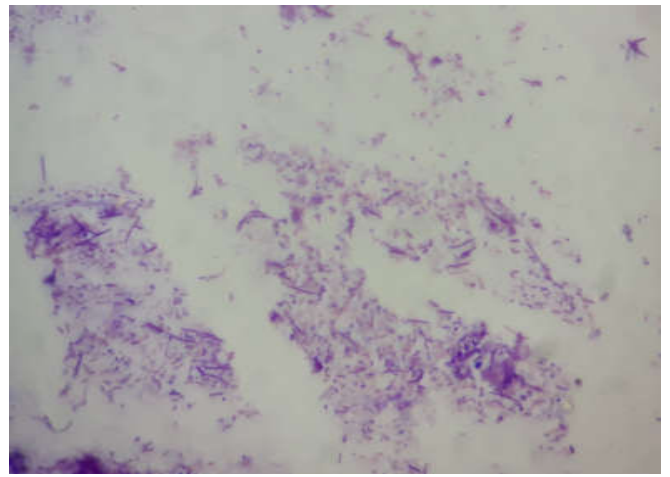

Figure-1 Gram Stain Showing Gram Positive Bacilli

\section{Discussion}

Diphtheria is a fatal disease which spreads through respiratory droplets produced by cough or sneeze of infected person or carrier. The carriers (95\%) being more important source of infection than cases (5\%) [8]. Diphtheria, even though is a vaccine preventable disease still persists in India. Its major virulence lies in its ability to produce potent exotoxin which inhibits protein synthesis.

Because of effective immunization programme, children aged between 1 to 5 year are not commonly affected instead increased incidence has been observed in 5-15 years age group. Nandi et al., and Saikiaet al., reported $59 \%$ and $100 \%$ of cases in $>5$ years of age group respectively [8]. After 3 doses of vaccine, antibody develops in $94 \%$ to $100 \%$ of children. But antibody drops below protective levels if booster doses are not taken $[9,10]$.

Disease in the previously immunized individuals is milder and less likely to be fatal [9]. A serological survey of 396 children $<5$ years of age who received care at a medical center in Dade County revealed that $22 \%$ lacked protective immunity to diphtheria [11]. Poor primary immunization coverage and missed booster doses are the main reasons for persistence of the disease.

The clinical manifestations can vary from mild to severe to the life threatening depending on immune status of host and severity of infection [12]. In the present study, 6 year old boy had fever, throat pain, neck swelling, difficulty in breathing and membrane over tonsil. The mortality rate is $5 \%-10 \%$ which can

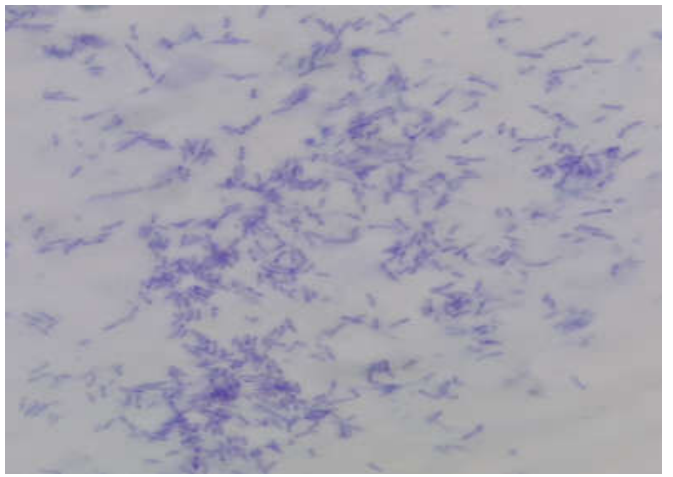

Figure-2 Albert Stain Showing Green Bacilli with black Granules

increase upto $20 \%$ in children below 5 years and adults over 40 years of age [13]. The diagnosis is based on clinical signs and symptoms plus laboratory confirmation. Because of the risk of respiratory obstruction, specific treatment should be started immediately on clinical suspicion without waiting for laboratory reports. Laboratory diagnosis is necessary only for confirmation of clinical diagnosis and initiating controlmeasures [14].

Documentation ofvaccination details, maintaining quality of vaccines and increasing vaccine coverage of primary and booster immunization against diphtheriaare necessary to decrease its incidence $[15,16]$.

\section{Conclusion}

Primary immunization coverage with three doses of diphtheria toxoid to infants without fail with booster doses is essential to maintain effective level of antibodies and to prevent its persistence and epidemiological transition of diphtheria.

Findings: Nil; Conflict of Interest: None initiated Permission from IRB: Yes

\section{References}

1. Manjunath Dandinarasaiah, Bhat Kemmannu Vikram, Naveen Krishnamurthy, A. C. Chetan, Abhineet Jain. Diphtheria Re-emergence: Problems Faced by Developing Countries. Indian J Otolaryngol Head Neck Surg; 2013; 65(4): 314-318.

2. Rohitha Jayamaha. Is Diphtheria Back? Sri Lankan Journal of Infectious Diseases; 2011; Vol.1(1): 27- 31. 
Case Report

3. P. Lakshmi Vasantha et al. A case of Diphtheria. Journal of Basic and Clinical Research;2016;3(1):35-38

4. Zasada AA. Corynebacterium diphtheriae infections currently and in the past. Przegl Epidemiol. 2015; 69 (3): 439-44, 569-74.

5. Basavaraja GV, Chebbi PG, Joshi S. Resurgence of diphtheria: clinical profile and outcome - a retrospective observational study. Int J ContempPediatr; 2016; 3:60-3

6. Phalkey RK, Bhosale RV, Joshi AP, et al. Preventing the preventable through effective surveillance: the case of diphtheria in a rural district of Maharashtra, India. BMC Public Health. 2013 Apr 8;13:317. doi: 10.1186/ 1471-2458-13-317.

7. Z Z Rashid, N A Mohamed, T S Fong. A Case Of Fatal Diphtheria In A Paediatric Patient. The Internet Journal of Microbiology; 2015; Volume 14 Number 1.

8. Das PP, Patgiri SJ, Saikia L, Paul D. Recent Outbreaks of Diphtheria in Dibrugarh District, Assam, India. J Clin Diagn Res. 2016 Jul;10(7):DR01-3. doi: 10.7860/JCDR/2016/20212.8144. Epub 2016 Jul 1.

9. Priya KPA, Kumar SS, Kannan A, Muralidharan U. A Child with Complicated Diphtheria in this Vaccine Era: A Case Report.Int J Sci Stud; 2017; 4(12):256-257.

10. Sunanda joshi, Nalini Mittal,Tarun Kumar Ravi. Diphtheria A Case Report-Early Diagnosis and Treatment Leads To Favourable Outcome. IOSR Journal of Dental and Medical, 2017; 16(4): 71-73.
11. Farizo KM, Strebel PM, Chen RT, et al. Fatal respiratory disease due to Corynebacterium diphtheriae: case report and review of guidelines for management, investigation, and control. Clin Infect Dis. 1993 Jan;16 (1): 59-68.

12. Meshram RM, Patil A. Clinical profile and outcome of diphtheria in central India: a retrospective observational study. Int J Contemp Pediatr; 2018; 5: 1600-5.

13. Mahantesh V.P, Aisha M.P, S. L. Lakkannavar, Sanjiva D.K and Subarna Roy. Diphtheria outbreak in rural North Karnataka, India. JMM Case Reports; 2014.

14. S.V. Savaskar, S.T. Bandichhode, P.S. Chhajed. Diphtheria in Children- Are we even close to control the menace? International Journal of Medical Pediatrics and Oncology; 2017; 3(3):106-109.

15. Parande MV, Roy S, Mantur BG, et al. Resurgence of diphtheria in rural areas of North Karnataka, India. Indian J Med Microbiol. 2017 Apr-Jun;35(2):247-251. doi: 10.4103/ijmm.IJMM_17_48.

16. Koripella Rama Lakshmi, C. Siva Kalyani, Perala Balamurali Krishna, N. Lakshmi, P. Anusha and Sulakshana Sony Cheemala. A Report of Three Cases of Diphtheria in a Tertiary Care Hospital. Int. J. Curr. Microbiol. App.Sci.; 2016;5(4): 675-680.

\section{How to cite this article?}

Wadekar M.D, Sathish J.V. Resurgence of Diphtheria- A case report. Trop J Path Micro 2018;4(6):434-436. doi:10.17511/jopm.2018.i06.03. 